\title{
Article \\ Thermally-Induced Shape-Memory Behavior of Degradable Gelatin-Based Networks
}

\author{
Axel T. Neffe ${ }^{1}$, Candy Löwenberg ${ }^{1}$, Konstanze K. Julich-Gruner ${ }^{1}$, Marc Behl ${ }^{1}$ and Andreas Lendlein ${ }^{1,2, *}$ (D) \\ 1 Institute of Active Polymers and Berlin-Brandenburg Center of Regenerative Therapies, Helm-holtz-Zentrum \\ Hereon, 14513 Teltow, Germany; axel.neffe@hereon.de (A.T.N.); candy.loewenberg@web.de (C.L.); \\ julich-gruner@helmholtz-muenchen.de (K.K.J.-G.); marc.behl@hereon.de (M.B.) \\ 2 Institute of Chemistry, University of Potsdam, 14476 Potsdam, Germany \\ * Correspondence: andreas.lendlein@hereon.de
}

Citation: Neffe, A.T.; Löwenberg, C.; Julich-Gruner, K.K.; Behl, M.;

Lendlein, A. Thermally-Induced Shape-Memory Behavior of Degradable Gelatin-Based Networks. Int. J. Mol. Sci. 2021, 22, 5892.

https://doi.org/10.3390/ijms22115892

Academic Editor:

Marta Fernández-García

Received: 22 April 2021

Accepted: 25 May 2021

Published: 31 May 2021

Publisher's Note: MDPI stays neutral with regard to jurisdictional claims in published maps and institutional affiliations.

Copyright: (C) 2021 by the authors Licensee MDPI, Basel, Switzerland. This article is an open access article distributed under the terms and conditions of the Creative Commons Attribution (CC BY) license (https:// creativecommons.org/licenses/by/ $4.0 /)$.

\begin{abstract}
Shape-memory hydrogels $(\mathrm{SMH})$ are multifunctional, actively-moving polymers of interest in biomedicine. In loosely crosslinked polymer networks, gelatin chains may form triple helices, which can act as temporary net points in $\mathrm{SMH}$, depending on the presence of salts. Here, we show programming and initiation of the shape-memory effect of such networks based on a thermomechanical process compatible with the physiological environment. The SMH were synthesized by reaction of glycidylmethacrylated gelatin with oligo(ethylene glycol) (OEG) $\alpha, \omega$-dithiols of varying crosslinker length and amount. Triple helicalization of gelatin chains is shown directly by wide-angle $X$-ray scattering and indirectly via the mechanical behavior at different temperatures. The ability to form triple helices increased with the molar mass of the crosslinker. Hydrogels had storage moduli of $0.27-23 \mathrm{kPa}$ and Young's moduli of $215-360 \mathrm{kPa}$ at $4{ }^{\circ} \mathrm{C}$. The hydrogels were hydrolytically degradable, with full degradation to water-soluble products within one week at $37^{\circ} \mathrm{C}$ and $\mathrm{pH}=7.4$. A thermally-induced shape-memory effect is demonstrated in bending as well as in compression tests, in which shape recovery with excellent shape-recovery rates $R_{r}$ close to $100 \%$ were observed. In the future, the material presented here could be applied, e.g., as self-anchoring devices mechanically resembling the extracellular matrix.
\end{abstract}

Keywords: shape-memory hydrogel; active polymer; biopolymer; mechanical properties; degradation

\section{Introduction}

The large variety of functional groups present in biopolymers such as nucleic acids and proteins gives rise to thermodynamically preferred conformations of such biomacromolecules in an aqueous environment [1]. These conformations, typically referred to as secondary structures (short-range interactions), tertiary structures (overall conformation of a single chain), and quarternary structures (overall structure involving several polymer chains) are related to the non-covalent interactions between the functional groups and with water as well as the stereoelectronic effects of substituents along the chain. Protein conformations are generally much more studied and better understood than, e.g., polysaccharide conformations. The adoption of preferred conformations is sequence (primary structure)-dependent [2], and is therefore inherently included information. The conformation is associated with the biological function of the protein, such as specificity in biological interactions $[3,4]$ or its mechanical performance [5,6]. As the conformations are based on non-covalent interactions, they can be altered, and, potentially, switched "on" or "off", by changing the environment, such as $\mathrm{pH}$, presence and concentration of ions or individual molecules, or temperature. This has inspired utilizing biopolymers as switching segments in shape-memory polymers (SMP). In addition, such biopolymer-based switching segments might impart degradability into the SMP [7,8], resulting in multifunctional materials [9]. Shape-memory hydrogels (SMH) are SMPs formed from hydrophilic polymers that are swollen in water $[10,11]$. These typically resemble the extracellular matrix in mechanical 
behavior as well as allow diffusion of nutrients so that SMH are of especial interest for biomedicine.

While a metal coordination of carboxymethyl cellulose derivatives [12,13] contains bio-polymer-based switching segments, the so-formed temporary net points do not occur in nature in this way. In contrast, several proteins have been used as components or blueprints in shape-memory polymers, e.g., the switch between $\alpha$-helical and $\beta$-strand conformations upon water uptake and at different strain was utilized in keratin-based materials [14]. The $\mathrm{pH}$-dependent switching between an unordered and a $\beta$-strand conformation of a 20mer peptide was employed to form temporary net points in acrylate copolymers with grafted peptide groups [15]. Temperature-dependent adoption of $\beta$-strand-like structures has furthermore been shown for short, hydrogel-forming peptides containing aromatic groups, which consequently allowed shape fixation in SMP consisting of a double network [16].

Typical for collagen/gelatin systems is the association of three polymer strands into a triple helix, which typically dissociate upon heating to $\sim 35-37^{\circ} \mathrm{C}$ [17]. Biotechnologically produced $\mathrm{ABA}$ triblock peptides with collagen-like A blocks and lysine-containing $\mathrm{B}$ blocks that were covalently crosslinked with glutaraldehyde [18] showed a shape-memory effect after programming using the triple helix formation as temporary net points. This strategy, however, did not allow easy tailoring of the mechanical properties of the network. An interpenetrating double network consisting of a covalent polymeth-acrylate network and a physical gelatin network [19] likewise exploited the triple helix association, but required the synthetic polymer network for the shape-memory effect. Addition of graphene oxide incorporated near infrared sensitivity in that system [20]. Similar from the material design is a double network based on polymethacrylate and elastin [21], in which the temperaturedependent coiling of the protein chains is the basis for shape fixation.

We recently introduced a gelatin-based covalent network system that is formed by reacting glycidyl methacrylated gelatin (GMA-gelatin) with oligo(ethylene glycol) (OEG) $\alpha, \omega$-dithiols (Figure 1A) [22]. The approach to crosslink gelatin by a bifunctional crosslinker has in the past been demonstrated to be beneficial for effectively establishing a poly-mer network. As such a crosslinker can be varied in length and rigidity, network properties can be tailored without changing the crosslinking chemistry [23]. GMA-gelatin OEG networks are only loosely crosslinked so that the gelatin chains are flexible enough to adopt triple helices under favorable environmental conditions. In that study, we furthermore showed that the formation and dissociation of triple helices can be assisted by employing chaotropic or kosmotropic salts, and that in this way a salt-induced shape-memory effect could be realized. In comparison to the studies cited above, neither a biotechnological produced protein nor a second network is required; i.e., by simple polymer-analogous reactions the gelatin-based network could be established. The salt-based control of protein chain conformation in a hydrogel and exploiting it for a material function such as the shapememory effect [22] is of fundamental interest, however, the required salt concentrations are likely not compatible with a biological environment. It is therefore of interest to investigate whether the shape recovery of gelatin/OEG-based SMH can be initiated by a stimulus compatible with the physiological environment, and whether changes in the composition of the networks influences properties and functions of the SMH.

Here, we explore in detail the chain organization (by wide angle X-ray scattering) and mechanical properties (by rheology and tensile tests at different temperatures) of hydrogels formed by reacting glycidyl methacrylated gelatin with OEG $\alpha, \omega$-dithiols of varied length and in different ratios. Furthermore, the hydrolytic degradation of such networks is described, and the shape-memory behavior using temperature as stimulus is explored and quantified in bending and compression tests. The network formation and the molecular principle of the shape-memory effect are depicted in Figure 1. 


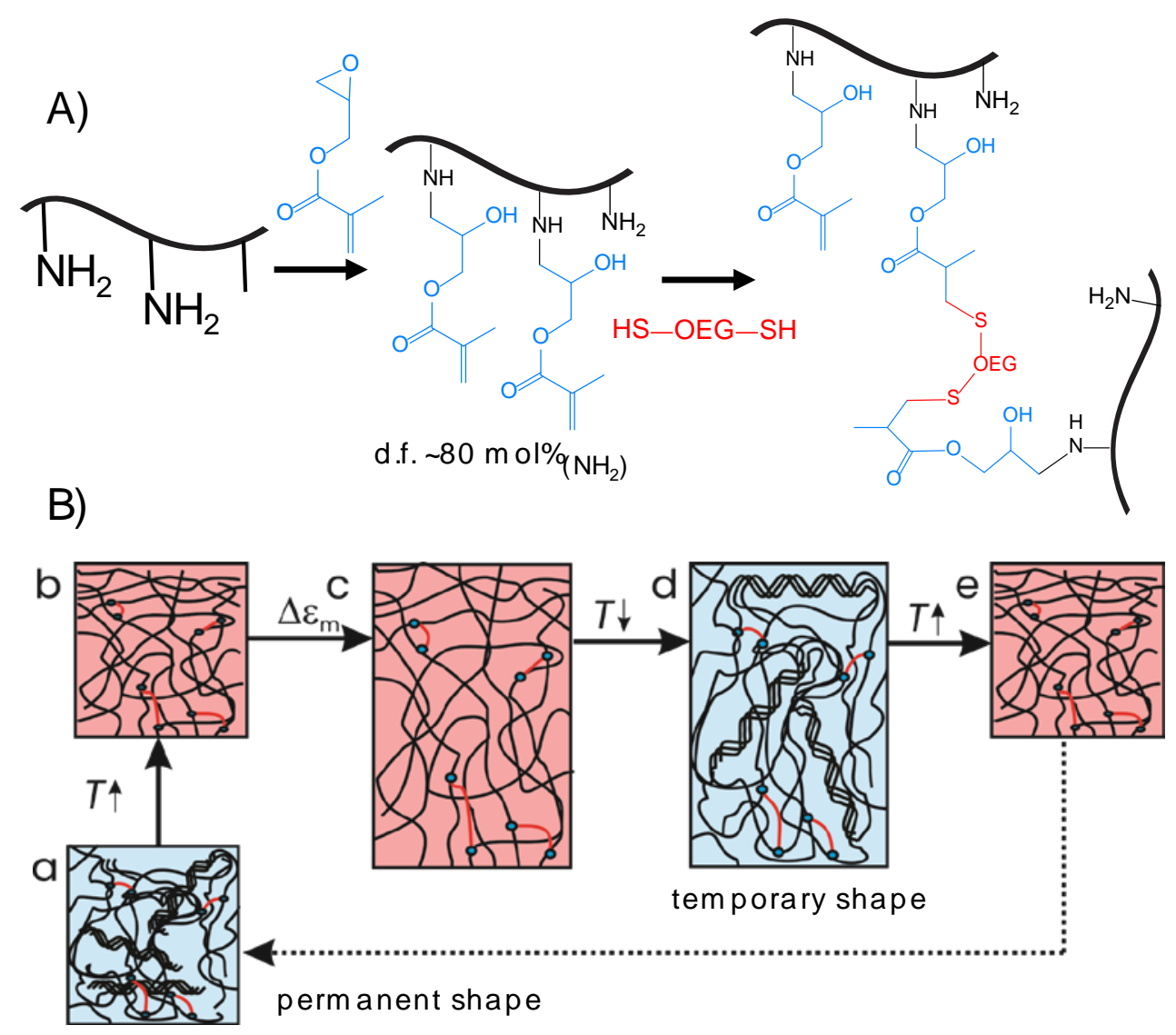

Figure 1. (A) Network formation is achieved in two steps: (i) functionalization of gelatin with glycidyl methacrylate; and (ii) crosslinking with an oligo(ethylene glycol) (OEG) $\alpha, \omega$-dithiol. (B) Molecular principle of the envisioned thermally-induced shape-memory effect of the investigated gelatin-based networks. The networks after synthesis at room temperature contain triple helices. (a) Heating leads to dissociation of the triple helices (b). Deformation at $T_{\text {high }}$ (c) and subsequent cooling (d) fixes the temporary shape of the material by triple helices acting as temporary net points. $(a \rightarrow d)$ is the programming of the material. Subsequent heating leads to the dissociation of the temporary net points and readoption of the permanent shape, the shape-memory effect (e). Returning to room temperature re-establishes status (a) without further shape change.

\section{Results and Discussion}

The synthesis of the gelatin-based network was performed by first functionalizing gelatin with double bonds by reaction with glycidyl methacrylate, and subsequent crosslinking the $20 \mathrm{wt} . \%$ GMA-gelatin solutions in water via thiol-Michael addition of OEG $\alpha, \omega-$ dithiols (Figure 1A). The constitution of the networks was varied by the length of the OEG crosslinkers $\left(M_{\mathrm{n}}=1000,1500\right.$ or $\left.3400 \mathrm{~g} \cdot \mathrm{mol}^{-1}\right)$ and ratio between thiol and methacrylate groups $(0.75,1,2$, or 3$)$. The networks are in the following referred to as G20_OEGy $(z)$, with $y=$ number average molar mass $M_{\mathrm{n}}$ of the OEG crosslinkers and $z$ the thiol:methacrylate molar ratio. The gel content $G$, which is a measure of network formation, and the volumetric swelling $Q$ of the G20_OEG1000(z) and G20_OEG3400(z) networks has been reported before [22] and is given in detail for the G20_OEG1500(z) in Supporting Information Table S1. As a general trend, a reduction of $G$ with increasing length of the crosslinker as well as with increasing $z$ was observed, though there were only small differences between G20_OEGy(0.75) and G20_OEGy(1) samples. The decrease of $G$ with the length of the crosslinker may reflect the somewhat lower reactivity of thiol end groups on larger, potentially coiled OEG, which may have led to a steric hindrance of the reactive group. Increasing $z$ leads to an increase of grafted OEG groups in comparison to OEG crosslinks. This may result in washing out not only of unreacted OEG, but also gelatin-g-OEG when determining G. Furthermore, when larger amounts of thiols are present, in addition to the Michael-type addition to the methacrylate groups thioester formation also may take place 
that would result in the formation of soluble OEG dimethacrylate thioesters (see Supporting Information Figure S1). $Q$ increased with $z$ as well as with OEG length, showing that the network density decreases upon these changes in composition. Temperature did not have an influence on $Q$. This is relevant, as otherwise the later-discussed shape recovery could partially be explained by a swelling effect upon heating, which is not the case here.

Dried gelatin network samples were investigated by wide angle $X$-ray scattering (WAXS, Figure 2 and Supporting Information Figure S2) to characterize the ability of the gelatin chains to adopt triple helices. Gelatin samples typically show three peaks in a WAXS analysis. Two narrow peaks appear at $2 \theta=7.5^{\circ}$ and $2 \theta=33^{\circ}$, which correspond according to Bragg's law to distances of $1.1 \mathrm{~nm}$ (intermolecular distance between collagen triple helices, and indicative of triple helicity) and $0.29 \mathrm{~nm}$ (distance of amino acidic residues along the left-handed single helices) [24]. A third, broad peak signifies the amorphous chain organization $\left(2 \theta \sim 21^{\circ}, \mathrm{d} \sim 0.45 \mathrm{~nm}\right)$. In all investigated samples, a peak at $2 \theta=7.5^{\circ}$ was observed and hence triple helices, which are the envisioned prerequisite for shape fixation of temporary shapes, were formed. By relating the area under the peak corresponding to the triple or single helix to the overall area under the curve, an index for the single and triple helical content can be calculated (Supporting Information Table S2). It should be noted that these indices are not an absolute value of helical content, as even compounds nearly completely adopting a triple helical conformation also show scattering resulting in an amorphous halo. However, the index can be employed to discuss changes in the ability or tendency to form triple helices $[23,25]$ and the association of them to fibrils. Here, the triple- and single helical indices $\left(X_{\mathrm{TH}}\right.$ and $\left.X_{\mathrm{SH}}\right)$ were higher for the G20_OEG3400( $\left.z\right)$ networks (5.6-6.1 $\pm 0.5 \%$ ) compared to the networks formed with shorter OEG (3.9-4.6 \pm $0.2 \%)$. This may translate into a higher shape-fixity ratio for the G20_OEG3400(z) when programming samples for an SME compared to the other networks. No changes were observed for different thiol:methacrylate molar ratios. The increased tendency for adopting triple helices with increasing chain length of the crosslinker may be explained by the larger degree of freedom for individual chains in such networks.

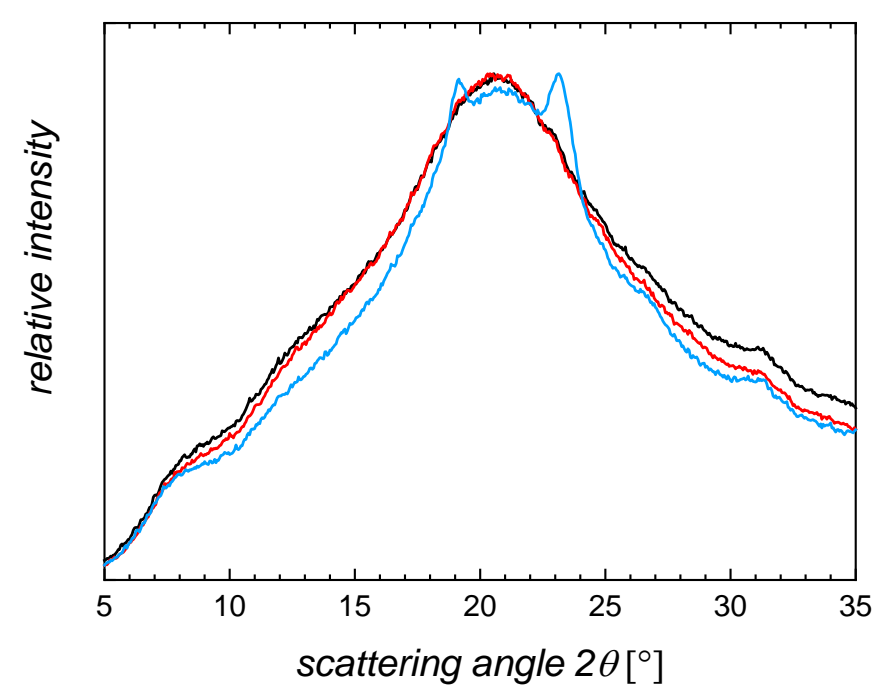

Figure 2. Wide angle X-ray scattering (WAXS) curves of dried G20_OEG1000(1) (black), G20_OEG1500(1) (red), and G20_OEG3400(1) (blue) networks at ambient temperature.

The mechanical properties of the hydrogels were evaluated in two setups: by rheology (Figure 3) and by tensile tests (Figure 4). The equilibrium swollen hydrogels exhibited storage moduli $G^{\prime}$ between $270 \pm 100 \mathrm{~Pa}$ and $22.8 \pm 1.2 \mathrm{kPa}$. A decrease of $G^{\prime}$ was observed with increasing chain length of the crosslinker and increasing $z$, mirroring the effects and rationale also observed and given for $Q$. Furthermore, $G^{\prime}$ decreased when increasing the temperature, with a median transition temperature $T_{\text {trans }}=25 \pm 3{ }^{\circ} \mathrm{C}$ determined in oscillation. In an additional experimental setup, the transition was investigated in rheological 
compression experiments (Supporting Information Figure S3) and was in this setup 28 $\pm 2{ }^{\circ} \mathrm{C}$. This observation demonstrated the temperature sensitivity of the mechanical properties and can be attributed to the disaggregation of gelatin triple helices above $T_{\text {trans, }}$ which consequently reduced the net point density. At temperatures below $T_{\text {trans }}$ the gelatin chains self-assemble to helices acting as additional net points. Consequently, at temperatures below $T_{\text {trans }}\left(T_{\text {low }}\right)$ the hydrogels contain permanent net points, formed by covalent crosslinking, and additional temporary net points, formed by helicalization of the gelatin, while at temperatures above $T_{\text {trans }}\left(T_{\text {high }}\right)$ only the permanent net points contributed to the network strength. The transition temperature is notably lower than in non-crosslinked gelatin $\left(T_{\text {trans }} \sim 35^{\circ} \mathrm{C}\right)[26]$, which suggests that the length of the formed triple helices in the networks studied here is quite limited.

With increasing OEG chain length the difference between the initial plateau of $G^{\prime}$ at $T_{\text {low }}$ and the plateau of $G^{\prime}$ at $T_{\text {high }}$ was increasing. This corresponds to the finding from the WAXS studies that these hydrogels were more prone to adopt triple helical conformations, and therefore are understood to have a higher percentage of temporary net points that are cleaved at $T_{\text {high }}$ compared to the studied networks with low OEG length. This observation was in agreement with the literature, revealing that the number of physical net points formed by self-organization into helices influences the difference between $G^{\prime}\left(T_{\text {low }}\right)$ and $G^{\prime}\left(T_{\text {high }}\right)[27]$.
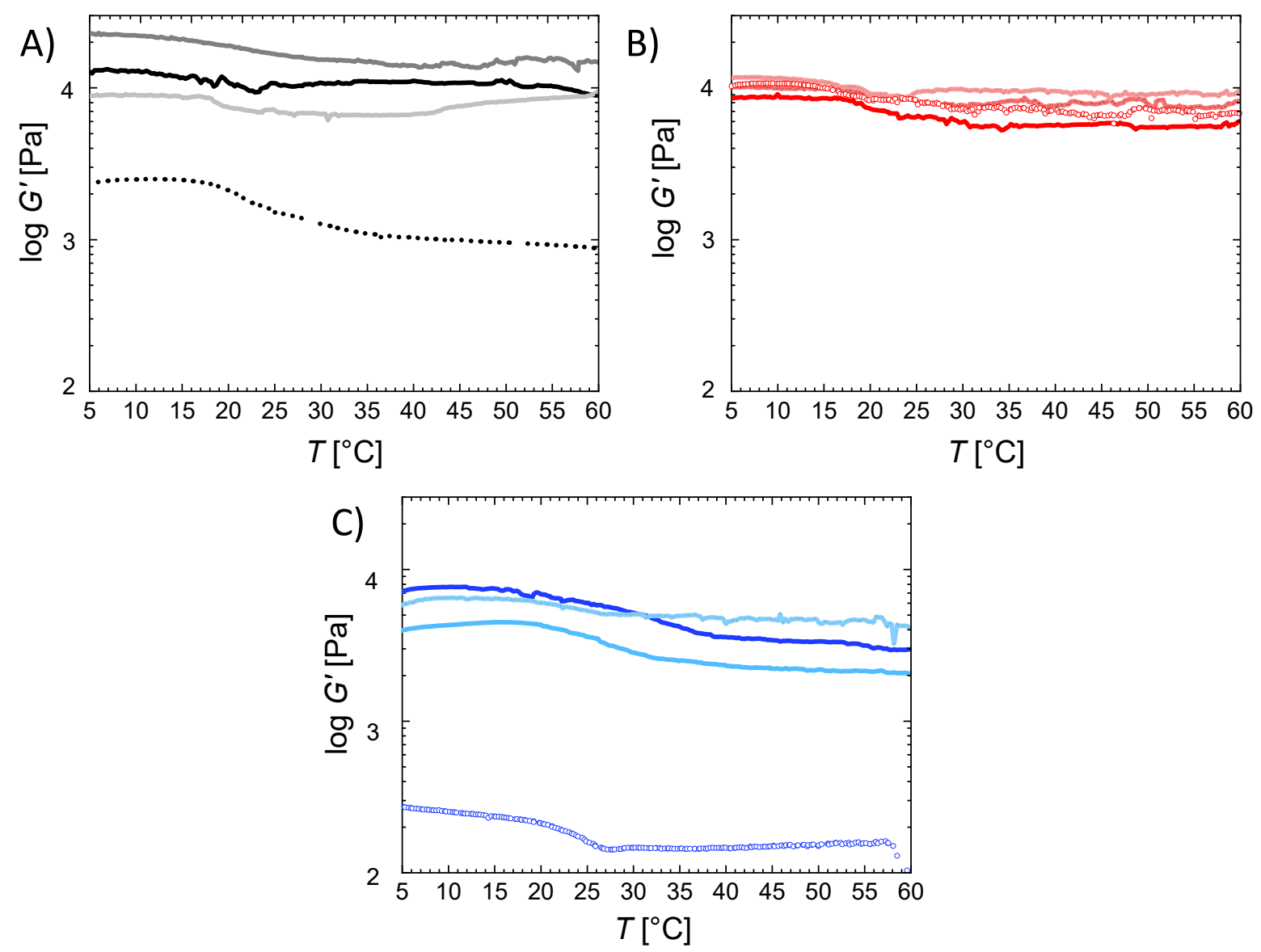

Figure 3. Storage modulus G' of (A) G20_OEG1000(z), (B) G20_OEG1500(z) and (C) G20_OEG3400(z) hydrogels at different temperatures. $\mathrm{z}=0.75(---), 1(---), 2(---)$, and $3(--\mathrm{O} \bigcirc \mathrm{O} \mathrm{O})$. 
The uniaxial tensile tests (values in Figure 4, exemplary curves in Supporting Information Figure S4) were performed on swollen samples under water at two different temperatures $\left(T_{\text {low }}=4{ }^{\circ} \mathrm{C}\right.$ and $T_{\text {high }}=55^{\circ} \mathrm{C}$ ), with covalent as well as temporary net points due to triple helicalization expected at $T_{\text {low }}$, and an amorphous network with covalent net points at $T_{\text {high }}$. The hydrogels accordingly showed increased Young's moduli $E$, elongation at break $\varepsilon_{\mathrm{b}}$, and tensile strength $\sigma_{\max }$ at $T_{\text {low }}$ compared to $T_{\text {high }}$. At $T_{\text {high, }}$, the helices disaggregated, resulting in less resistance against uniaxial stretching compared to $T_{\text {low. }}$. $\varepsilon_{\mathrm{b}}$ was between $51 \pm 23 \%$ and $163 \pm 35 \%$. Lowest $\varepsilon_{\mathrm{b}}$ values were observed for hydrogels with $z=$ 1 and $M_{n, \mathrm{OEG}}$ of $1000 \mathrm{~g} \cdot \mathrm{mol}^{-1}$, indicating the highest degree of crosslinking. Additionally, $\varepsilon_{\mathrm{b}}$ was increasing with increasing OEG chain length. The hydrogel's $\sigma_{\max }$ was between $0.05 \pm 0.01 \mathrm{MPa}$ and $0.36 \pm 0.10 \mathrm{MPa}$, and was lower at $T_{\text {high }}(0.05-0.1 \mathrm{MPa})$ than at $T_{\text {low }}$ $(0.26-0.36 \mathrm{MPa})$. A comparison of $\sigma_{\max }$ values at constant temperature showed almost no correlation of OEG chain length or amount and $\sigma_{\max }$, as the obtained data were all within the margin of error. However, a minor trend could be shown at $T_{\text {low }}$, at which an increase of $\sigma_{\max }$ was correlating with an increasing OEG length. The Young's modulus $E$ was in the range of $83 \pm 25 \mathrm{kPa}$ to $356 \pm 32 \mathrm{kPa}$. An increase in OEG length led to a decrease in $E$, which was due to an increase in mesh size and therefore increased flexibility of the polymer chains within the network. Indeed, the increase in OEG content showed different effects on $E$, depending on the temperature. At $T_{\text {low }}, E$ increased with increasing $z$, attributed to the increase of dangling ends and consequently a decrease in number of permanent net points. This furthermore increased the ability of helix formation acting as temporary net points resulting in an increase of the overall net point density, which led to an increase in material resistance against uniaxial deformation. At $T_{\text {high, }}$ no influence of OEG content on $E$ was observed, as only the permanent net points contributed to the mechanical properties.
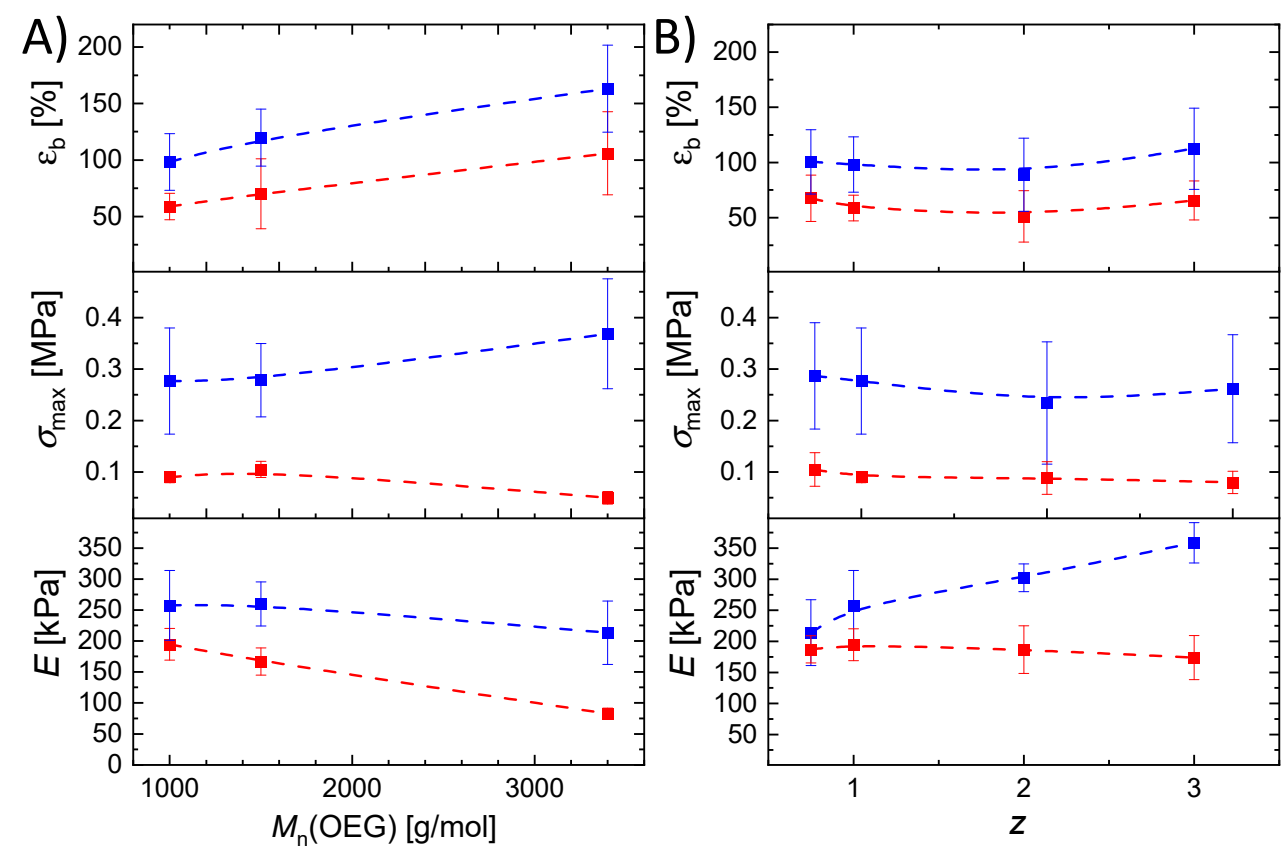

Figure 4. Elongation at break $\left(\varepsilon_{\mathrm{b}}\right)$, tensile strength $\left(\sigma_{\max }\right)$, and Young's modulus $(E)$ of the gelatin-based hydrogels under variation of OEG number average molar mass (A), or thiol:alkene molar ratio of the G20_OEG1000(z) hydrogels (B), determined in tensile tests at $4{ }^{\circ} \mathrm{C}$ (blue) and $55^{\circ} \mathrm{C}$ (red) in a water chamber. The lines are added as a guide to the eye.

While the OEG chains themselves are not hydrolytically degradable, they are connected to the gelatin backbone by ester bonds, which can be hydrolytically cleaved. This is also true for the amide bonds of the gelatin chains, which are however more stable to hydrolysis than esters. The degradation of the network was studied by quantifying the mass loss, the change of water uptake, as well as the change of mechanical properties of 
the G20_OEGy(1) networks during degradation (Figure 5 and Supporting Information Figure S5).

The rate of hydrolytic degradation was dependent on the chain length of the crosslinker. An increase of the chain length led to an increase in mass loss and water uptake during degradation, attributed to the increasing mesh size and hydrophilicity of the hydrogel, both contributing to a faster diffusion of water into the network and, potentially, also to a faster release of fragments. The change of mechanical strength of the hydrogels was investigated by rheology recording the storage modulus in temperature-dependent oscillation tests. $G^{\prime}$ strongly depended on the degradation time and was decreasing by about two orders of magnitude during degradation. The effect was more evident for increased chain length of the OEG crosslinker, as rationalized above regarding the mass loss and water uptake. Furthermore, the difference between the plateau at $T_{\text {low }}$ and $T_{\text {high }}$ increased with increasing degradation time. This is likely due to the decreasing net point density and resulting increase in mesh size during degradation, which increases the flexibility of the polymer chains. At increased degradation time the amount of helices was increased, which is why a sharper transition can be observed, compared to the non-degraded hydrogels.

In comparison to hydrolytic degradation experiments of other gelatin-based hydrogels, where the complete degradation took more than six weeks $[28,29]$, the GMA-OEG hydrogels showed a faster degradation. This suggests that it is not the hydrolysis of the main chains, but rather the hydrolysis of the crosslinker that is here the rate determining step of the degradation. While the oligoethers are not hydrolytically degraded, the ester bonds from the original glycidyl methacrylate group are likely the primary point of attack. A further experiment supports this hypothesis: an SDS-polyacrylamide gel electrophoresis (PAGE) was conducted from the gelatin starting material and the partially degraded gelatin-based networks. In the PAGE, no gelatin fragments were observed (Supporting Information Figure S6). It can be furthermore speculated that in systems with a high thiol:methacrylate molar ratio, and hence free thiol groups, degradation may be assisted by ester-thioester exchange reactions according to Supporting Information Figure S1.

The principle of characterization of the shape-memory properties by bending experiments is depicted in Figure 6A. The hydrogels were cut into stripes and bent by $180^{\circ}$ after heating above $T_{\text {trans }}$ (to $55^{\circ} \mathrm{C}$ ). The deformed hydrogel stripes were cooled below $T_{\text {trans }}\left(\right.$ to $4{ }^{\circ} \mathrm{C}$ ) for $8 \mathrm{~h}$, while keeping the applied deformation to allow helicalization of the gelatin chains acting as physical net points to fix the temporary shape. Then, the applied deformation was removed obtaining the temporary shape. The permanent shape was

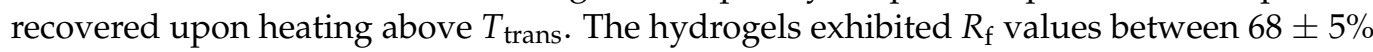
and $97 \pm 3 \%$, where $R_{\mathrm{f}}$ was increasing with increasing OEG chain length (Figure 6B). This observation was related to the higher degree of triple helix formation fixing the temporary shape as temporary net points. Additionally, hydrogels with $z=1$ exhibited the lowest $R_{\mathrm{f}}$ (Figure 6C). Because the $z=1$ networks have the highest net points density of the investigated hydrogels, the formation of helices acting as net points for the fixation of the temporary shape is here the lowest. Conclusively, the ability for the fixation of the temporary shape directly correlated to the amount of helices in the network. All hydrogels exhibited excellent $R_{\mathrm{r}}$ of $100 \%$, independent of the OEG chain length and OEG content, revealing that the recovery of the permanent shape is independent of the helix content.

A second method for the determination of the shape-memory properties was compression testing (Figure 7A). Here, the hydrogels were compressed to $35-50 \%$ of their initial height at $T=55^{\circ} \mathrm{C}$, i.e., above $T_{\text {trans }}$ of the gelatin chains. Afterwards, the hydrogels were cooled to $T=4{ }^{\circ} \mathrm{C}$ for at least $8 \mathrm{~h}$. By increasing the temperature again above $T_{\text {trans, }}$, the initial shape was recovered. Since volumetric shrinking or swelling could hinder or distort the observation and quantification of the SME, the volume of the hydrogel samples in the permanent shape $\left(V_{\text {perm }}=46 \pm 3 \mathrm{~cm}^{3}\right)$ and in the temporary shape $\left(V_{\text {temp }}=49 \pm 3 \mathrm{~cm}^{3}\right)$ were determined by measuring the outer dimensions of the gels. As the values were within the margin of error, the volume of the samples is understood to have no major influence on the SME, and shape change only occurs due to entropy-elastic recoiling, i.e., an SME. 
This corresponds to the observation that the degree of swelling $Q$ does not change with the temperature for the investigated samples, furthermore supporting the understanding that a true shape-memory effect was observed. In compression mode, the hydrogels exhibited excellent $R_{\mathrm{f}}$ (from $94 \pm 6$ to $100 \pm 5 \%$ ) and $R_{\mathrm{r}}$ values (100 $\pm 5 \%$ ), and no influence of the hydrogel composition on the shape-memory properties was observed (Figure 7B,C). In contrast to the $R_{\mathrm{f}}$ values determined by bending tests, the $R_{\mathrm{f}}$ values determined by compression tests were higher. This observation can be related to the surface-to-volume ratio of the sample. In compression tests, the whole sample could contribute to the shape fixation, while in bending experiments only the small part of the bent area was involved in the shape fixation. While a complete shape recovery was observed for all samples in both SME setups, it should be noted that the determined $R_{\mathrm{f}}$ may potentially reduce over time because of creep, which however has not been investigated in this study.

In the design of thermally-induced shape-memory hydrogels, one can distinguish between the thermal transition temperature associated with the switching domain $\left(T_{\text {trans }}\right)$ and the switching temperature $\left(T_{\mathrm{SW}}\right)$, at which the shape change is observed. These can be different because of the influence of heat transfer and dissipation, the water diffusion rate, as well as geometric effects of the investigated sample. In the current example, $T_{\text {trans }}$ as determined by rheology $\left(25 \pm 3{ }^{\circ} \mathrm{C}\right.$ in oscillation, $28 \pm 2{ }^{\circ} \mathrm{C}$ in compression) was excellently correlating with $T_{\mathrm{sw}}\left(26 \pm 3^{\circ} \mathrm{C}\right)$. This means that the shape recovery is compatible with a physiological environment. While the shape recovery was quantified at $T_{\text {high }}=55^{\circ} \mathrm{C}$, a full recovery is also expected at $37^{\circ} \mathrm{C}$, though with a lower speed of recovery. Supporting Information Figure S7 and the Supporting Information Video V1 show the programming of a hydrogel strip as a helix and the recovery of the permanent form.
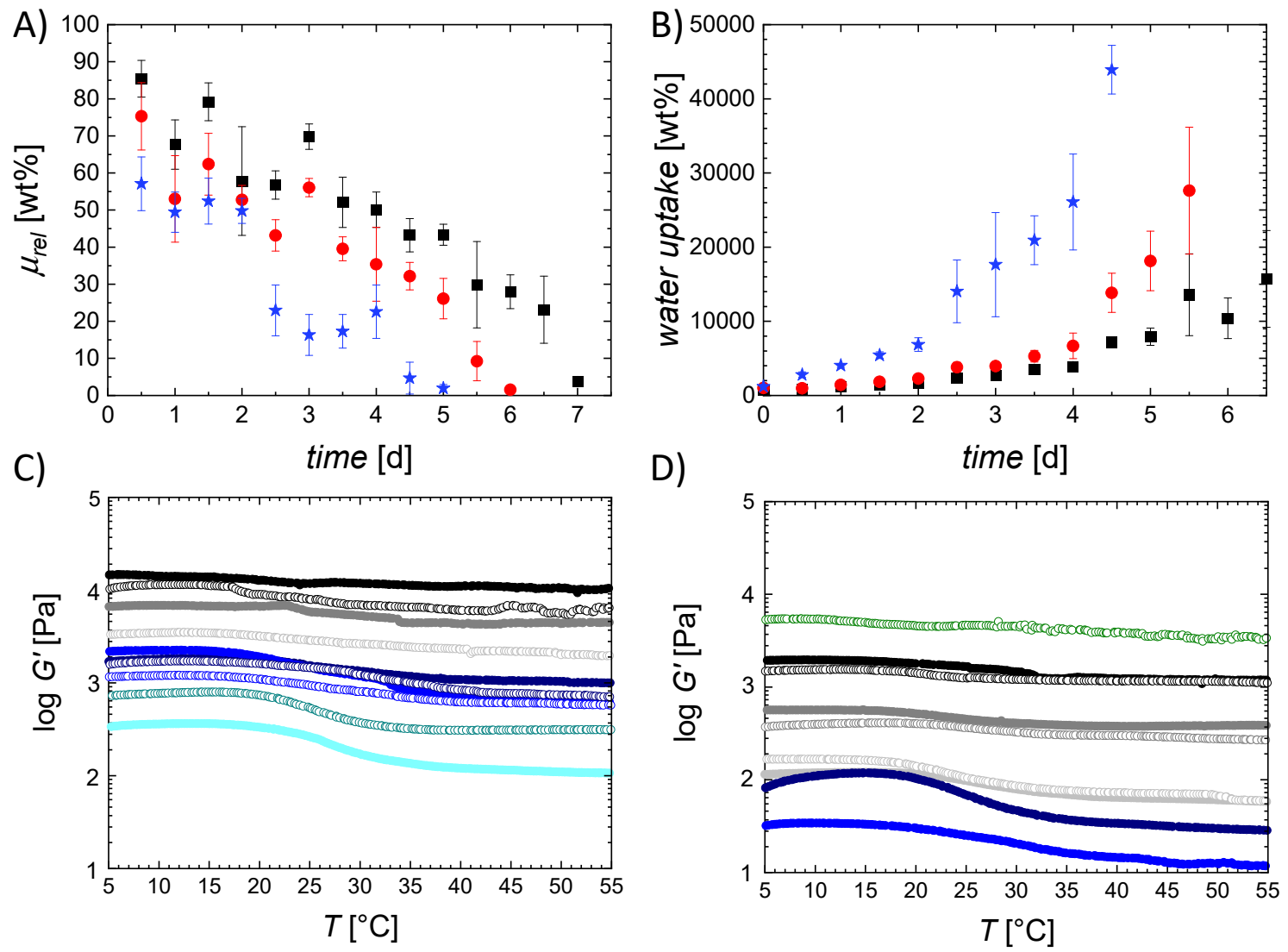

Figure 5. Hydrolytic degradation of G20_OEGy(z) hydrogels at $37^{\circ} \mathrm{C}$ and $\mathrm{pH}=7.4$ : (A) remaining mass $\mu_{\text {rel }}$ and (B) water uptake $H$ over time. G20_OEG1000(1): black, G20_OEG1500(1): red, G20_OEG3400(1): blue. C/D) Rheological behavior of

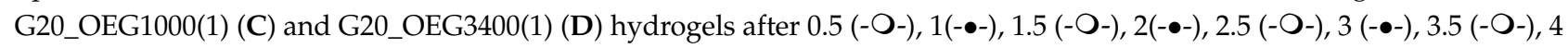

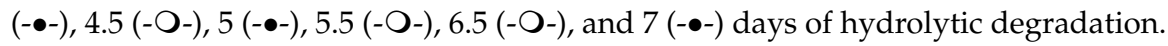


A)

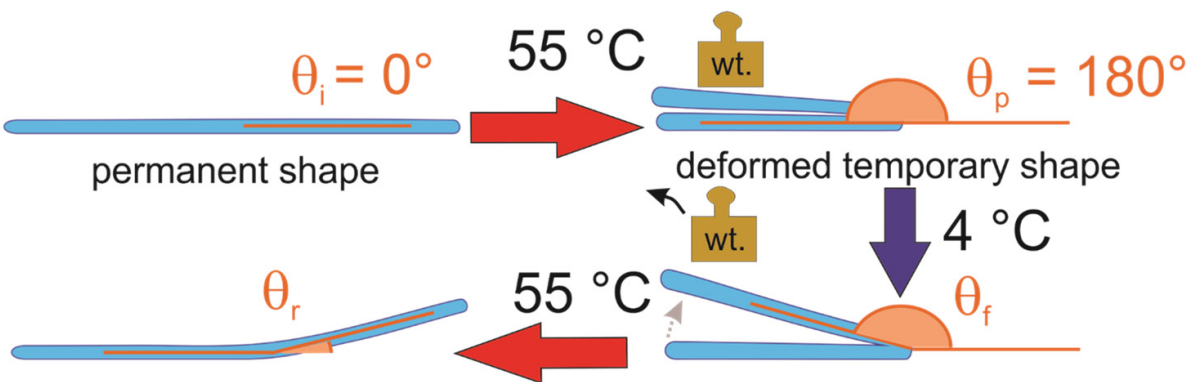

recovered permanent shape

fixed temporary shape

B)

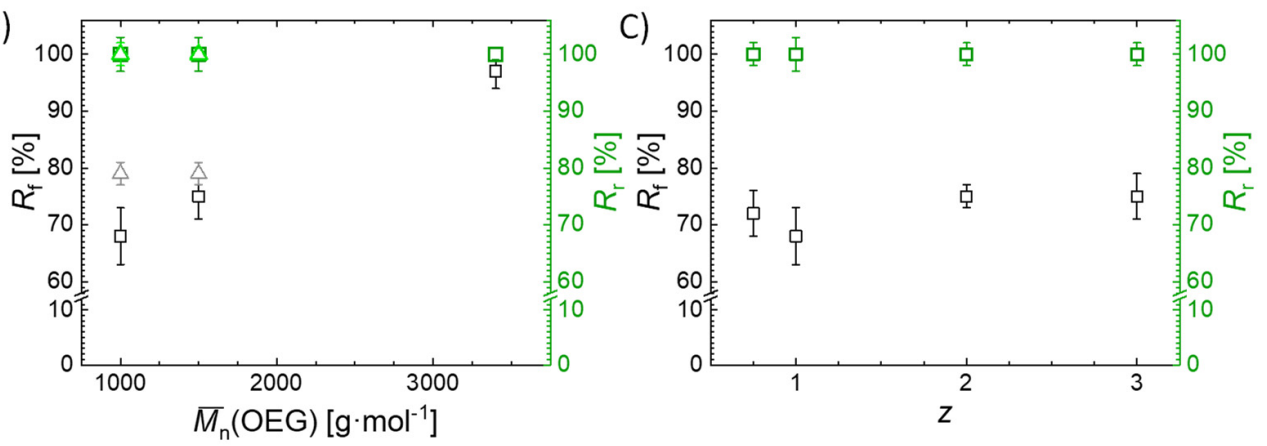

Figure 6. Shape-memory properties determined by bending experiments with temperature as stimulus. (A) Schematic illustration of the experimental setup for the determination of shape-fixity and shape-recovery ratios. $(\mathrm{B}) R_{\mathrm{f}}$ and $R_{\mathrm{r}}$ as a function of OEG chain length for G20_OEGy(z) hydrogels. (C) $R_{\mathrm{f}}$ and $R_{\mathrm{r}}$ as a function of OEG content for G20_OEG1000(z) hydrogels. $(\square: \mathrm{z}=1, \Delta: \mathrm{z}=2)$.

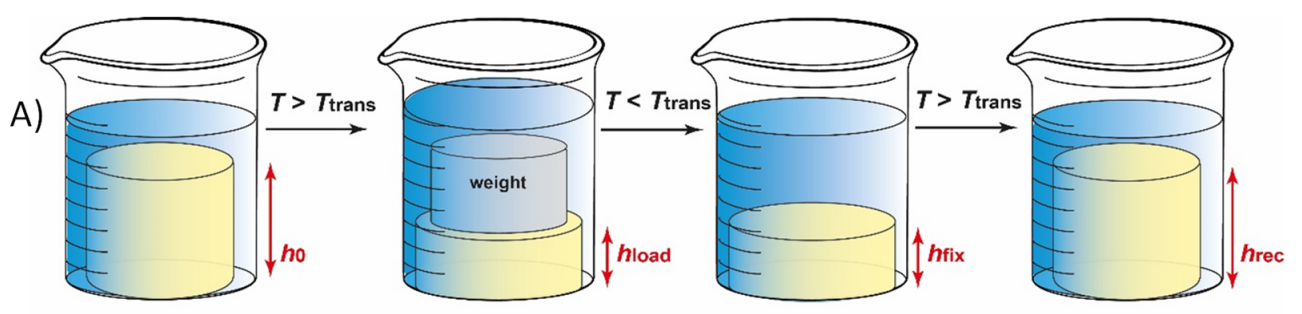

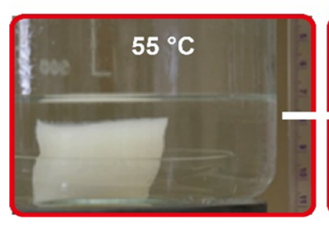

B)

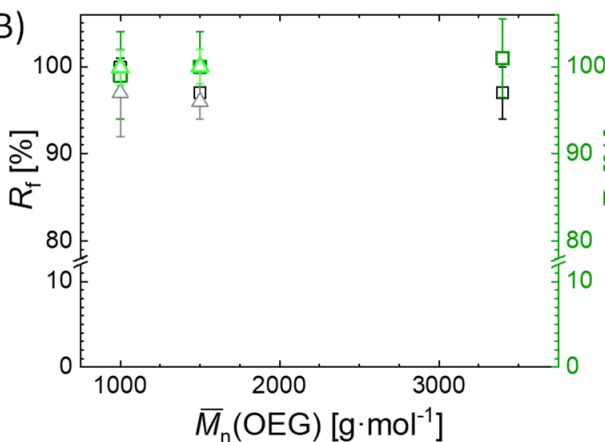

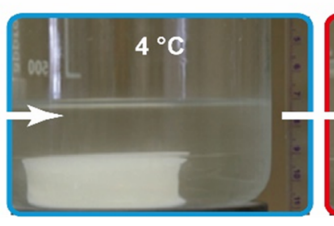
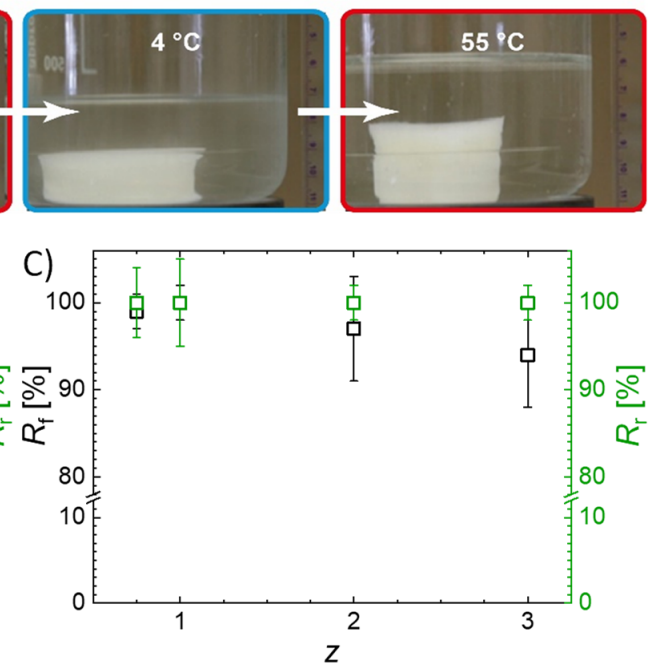

Figure 7. Shape-memory properties determined by compression experiments with temperature as stimulus. (A) Schematic illustration and images of the experimental setup. (B) $R_{\mathrm{f}}$ and $R_{\mathrm{r}}$ as a function of OEG chain length for G20_OEGy(z) hydrogels. (C) $R_{\mathrm{f}}$ and $R_{\mathrm{r}}$ as a function of OEG content for G20_OEG1000 (z) hydrogels. ( $\square: \mathrm{z}=1, \Delta: \mathrm{z}=2$ ). 


\section{Materials and Methods}

\subsection{Materials}

Gelatin (type A, 200 bloom), and coomassie blue were purchased from Fluka (Munich, Germany). Glycidyl methacrylate, OEG1000, OEG1500, OEG3400, TNBS, sodium chloride, sodium thiocyanate, sodium bicarbonate, ethanol, hydrochloric acid, diethyl ether, acetic acid, dichloromethane, methanol, THF, DMSO-D6, $\mathrm{D}_{2} \mathrm{O}$, and SDS-PAGE sample buffer were obtained from Sigma Aldrich (Munich, Germany). Sodium carbonate, tris(hydroxymethyl)-aminomethane, glycine, SDS, ammonium sulfate, sodium sulfate, magnesium chloride, disodium-hydrogenphosphate, and sodium dihydrogenphosphate were purchased from Merck (Darmstadt, Germany). All solvents and reagents were used without further purification.

\subsection{GMA-Gelatin}

Gelatin (10 wt.\%) was dissolved in bicarbonate buffer $(0.05 \mathrm{M}, \mathrm{pH}$ 9.6: $1.59 \mathrm{~g}$ sodium carbonate and $2.93 \mathrm{~g}$ sodium bicarbonate in $1 \mathrm{~L}$ water) at $50^{\circ} \mathrm{C}$. GMA was added with a dropping funnel, and the reaction was stirred at $50^{\circ} \mathrm{C}$ for $3 \mathrm{~h}$. The product was precipitated in 5 vol. eq. ethanol at room temperature (RT). The GMA-gelatin was cut into smaller pieces that were dried at $40^{\circ} \mathrm{C}$ under reduced pressure. The degree of functionalization was determined by 2,4,6-Trinitrobenzenesulfonic acid (TNBS) assay.

\subsection{TNBS Assay}

Gelatin or GMA-gelatin (11 mg) was dissolved in $1 \mathrm{~mL}$ of 4 wt.\% $\mathrm{NaHCO}_{3}(\mathrm{pH} 8.5$ ) containing $1 \mathrm{~mL}$ of $0.5 \mathrm{wt} . \%$ TNBS. The reaction mixture was shaken mildly at $40{ }^{\circ} \mathrm{C}$ for $4 \mathrm{~h} ; 3 \mathrm{~mL} 6 \mathrm{M} \mathrm{HCl}$ was added and the mixture was heated at $120^{\circ} \mathrm{C}$ for $1 \mathrm{~h}$. After cooling to $25^{\circ} \mathrm{C}, 5 \mathrm{~mL}$ of water was added. The mixture was extracted three times with $20 \mathrm{~mL}$ ethyl ether. A $5 \mathrm{~mL}$ aliquot of the aqueous phase was heated for $20 \mathrm{~min}$ in a hot water bath to evaporate the residual ether. The aliquot was diluted to $20 \mathrm{~mL}$ with water and the absorbance was measured at $346 \mathrm{~nm}$. All experiments were performed in triplicates and read against a blank that was prepared by the same procedure while adding the $\mathrm{HCl}$ before the addition of TNBS. The degree of functionalization (DF) was calculated according Equations (1) and (2), where $A$ is the measured absorbance at $346 \mathrm{~nm}, \mathrm{~V}$ the volume of the aliquot $(0.02 \mathrm{~L}), 1.46 \times 10^{4}$ the absorption coefficient of the 2,4,6-trinitrophenyl derivative, $l$ the cell path length $(1 \mathrm{~cm}), \mathrm{m}$ the sample weight $(11 \mathrm{mg})$, and $\mathrm{n}_{\mathrm{NH} 2^{\circ}}$ the amount of free amino groups before functionalization $\left(3.48 \times 10^{-4} \mathrm{~mol} / \mathrm{g}\right)$.

$$
\begin{gathered}
n_{\mathrm{NH}_{2}}=\frac{2 \cdot A \cdot \mathrm{V}}{1.46 \times 10^{4} \cdot l \cdot \mathrm{m}} \\
D F=100-\frac{n_{\mathrm{NH}_{2}}}{n_{\mathrm{NH}_{2}^{0}}} \times 100 \%
\end{gathered}
$$

\subsection{Network Synthesis}

The networks were synthesized by dissolving $1 \mathrm{~g}$ GMA-gelatin in $5 \mathrm{~mL}$ water and addition of OEG dithiols with varying molar masses $\left(M_{n}=1000,1500\right.$, or $\left.3400 \mathrm{~g} \cdot \mathrm{mol}^{-1}\right)$ dissolved in $5 \mathrm{~mL}$ of water ( $20 \mathrm{wt} . \%)$. After stirring the reaction mixture for one minute, the mixture was cast into a Petri dish, followed by drying at $40^{\circ} \mathrm{C}$ overnight.

\subsection{Gel Content}

The gel content $G$ was determined by comparing the dry weight of the sample after extraction ( $24 \mathrm{~h}$ at r.t., changing the water eight times) ( $\left.\mathrm{m}_{\mathrm{extr}}\right)$ with the dry weight before extraction $\left(\mathrm{m}_{\mathrm{iso}}\right)$ according to Equation (3). These extracted samples were used in the further experiments.

$$
G=100 \% \cdot \frac{m_{\text {extr }}}{m_{\text {iso }}}
$$




\subsection{Rheology}

Rheological investigations were performed on equilibrium swollen samples on a Haake Rheowin Mars II or Haake Rheowin Mars III (Thermo Scientific, Karlsruhe, Germany) using a $20 \mathrm{~mm}$ plate-plate geometry. A solvent trap was placed above the sample to avoid water evaporation. Temperature ramp measurements were performed on three replicas with a controlled stress of $4 \mathrm{~Pa}$ and at a frequency of $1 \mathrm{~Hz}$, as the systems were in the linear viscoelastic range under these conditions. The heating rate was $1 \mathrm{~K} \cdot \mathrm{min}^{-1}$. A constant force of $1 \mathrm{~N}$ was used on the as-prepared hydrogels, while a constant force of $0.1 \mathrm{~N}$ was applied in the hydrolytically partially degraded networks. In rheological compression experiments for the determination of $T_{\text {trans, }}$ samples were compressed repeatedly to $50 \%$ of height and relaxed again, increasing the temperature from 10 to $50{ }^{\circ} \mathrm{C}$ in increments of $2{ }^{\circ} \mathrm{C}$ and registering the required force for the compression.

\subsection{Tensile Tests}

The mechanical properties were investigated with a tensile tester Zwick ZP 99 (Zwick $\mathrm{GmbH}$, Ulm, Germany), equipped with a force transducer of maximum $20 \mathrm{~N}$ in a water chamber (distilled water) at $T_{\text {low }}\left(4^{\circ} \mathrm{C}\right)$ and $T_{\text {high }}\left(55^{\circ} \mathrm{C}\right)$. The measurements were carried out with minimum 6 repetitions on dog bone-shaped samples (ISO 527-2/1BB, $30 \times 2 \mathrm{~mm}$ ) after determination of the sample thickness, registering engineering stress $\sigma$ and strain $\varepsilon$. The samples were elongated with a speed of $5 \mathrm{~mm} \cdot \mathrm{min}^{-1}$ using a preforce of $5 \mathrm{mN}$. $E$ was calculated manually as the slope of the initial linear segment of the tensile test curve, typically at strains $<2 \%$. Before the measurement, all samples were swollen to equilibrium in distilled water. To delete the thermal history, the samples were heated up to $55^{\circ} \mathrm{C}$ for $10 \mathrm{~min}$, and cooled for $8 \mathrm{~h}$ at $4{ }^{\circ} \mathrm{C}$ to allow helicalization.

\subsection{Wide Angle X-ray Scattering (WAXS)}

WAXS measurements were performed on dried samples on a Bruker D8 Discover with a 2D-detector from Bruker AXS (Karlsruhe, Germany) using 3 replicates for each sample. WAXS images were collected from gelatin films in transmission geometry with a collimator-opening of $0.8 \mathrm{~mm}$ at a sample-to-detector distance of $15 \mathrm{~cm}$. The X-ray generator was conducted at a voltage of $40 \mathrm{kV}$ and a current of $40 \mathrm{~mA}$, with $\mathrm{Cu}-\mathrm{K} \alpha$ radiation of a wavelength of $\lambda=0.154 \mathrm{~nm}$, covering a $2 \theta$ range of $\sim 3$ to $37^{\circ}$. An exposure time of $300 \mathrm{~s}$ per frame was used, and an empty sample holder was subtracted as background. The determination of the index of single and triple helicity $\left(\mathrm{X}_{\mathrm{TH}}, \mathrm{X}_{\mathrm{SH}}\right)$ was determined according to Equations (4) and (5):

$$
\begin{aligned}
X_{T H} & =\frac{100 \cdot A_{T H}}{A_{\text {amorph }}} \\
X_{S H} & =\frac{100 \cdot A_{S H}}{A_{\text {amorph }}}
\end{aligned}
$$

where $A_{\mathrm{TH}}=$ area under the peak related to the triple helices, $A_{\mathrm{amorph}}=$ area of the amorphous peak, and $A_{\mathrm{SH}}=$ area under the single helix peak. The margin of error was obtained in a manual fitting, wherefore it was quite small. In the following, the mean value of 6 fittings \pm s.d. is given. Instrumental contributions to the peak broadening were negligible. Primary data were corrected for geometric distortions (spatial correction) and the center and the distance of the sample to detector were calibrated utilizing the corundum standard.

\subsection{Determination of Shape-Memory Properties}

For the determination of the strain-fixity ratio $\left(R_{\mathrm{f}}\right)$ and the strain-recovery ratio $\left(R_{\mathrm{r}}\right)$ by bending, the equilibrium swollen hydrogels were cut into stripes $(5 \times 1 \mathrm{~cm})$. For programming, the samples with an initial angle $\theta_{\mathrm{i}}\left(=0^{\circ}\right.$ for the first cycle) were heated to $55^{\circ} \mathrm{C}$ and bent with an angle $\theta_{\mathrm{p}}=180^{\circ}$ in the middle of the stripe and subsequently 
cooled at $4{ }^{\circ} \mathrm{C}$ for $12 \mathrm{~h}$ while keeping the deformation. The temporary shape was obtained after release of the applied load and the angle of the fixed shape $\left(\theta_{\mathrm{f}}\right)$ was determined. The programmed samples were heated to $55{ }^{\circ} \mathrm{C}$ to recover the permanent shape. Finally, the angle of the recovered shape was measured $\left(\theta_{\mathrm{r}}\right)$. For the determination of the angles between the segments of the folded stripes, photographs of the stripes were recorded and analyzed by ImageJ. $R_{\mathrm{f}}$ and $R_{\mathrm{r}}$ were calculated according to Equations (6) and (7) as the average from five cycles:

$$
\begin{aligned}
& R_{f}=\frac{\theta_{f}-\theta_{i}}{\theta_{p}-\theta_{i}} \cdot 100 \% \\
& R_{r}=\frac{\theta_{f}-\theta_{r}}{\theta_{f}-\theta_{i}} \cdot 100 \%
\end{aligned}
$$

For the determination of the shape-memory properties in compression tests, the equilibrium swollen hydrogel cylinder (diameter of $4 \mathrm{~cm}$ and height of $3 \mathrm{~cm}\left(\mathrm{~h}_{0}\right)$ ) were heated to $55{ }^{\circ} \mathrm{C}$ and compressed to about $35-50$ height $\%\left(h_{\text {load }}\right)$. The hydrogels were immediately cooled to $4{ }^{\circ} \mathrm{C}$ for at least $8 \mathrm{~h}$ while keeping the compression, to enable the helicalization of the gelatin chains. Afterwards, the applied load was released and the height of the fixed shape was measured $\left(h_{\mathrm{fix}}\right)$. The temperature was raised to $55^{\circ} \mathrm{C}$, the initial shape was recovered, and the height of the recovered shape was measured $\left(h_{\text {rec }}\right) \cdot R_{\mathrm{f}}$ and $R_{\mathrm{r}}$ were calculated from 5 cycles according Equations (8) and (9).

$$
\begin{aligned}
& R_{f}=\frac{h_{f i x}-h_{0}}{h_{\text {load }}-h_{0}} \cdot 100 \% \\
& R_{r}=\frac{h_{\text {rec }}-h_{f i x}}{h_{0}-h_{f i x}} \cdot 100 \%
\end{aligned}
$$

\subsection{Degradation}

For degradation studies, the swollen hydrogels were punched in circular shape with a diameter in the wet state of $0.5 \mathrm{~cm}$ or $2 \mathrm{~cm}$ (depending on the analysis) and dried until constant weight was achieved. The $2 \mathrm{~cm}$ discs were used for the determination of the thermomechanical properties using rheology, while the $0.5 \mathrm{~cm}$ discs were used for determination of water uptake $(H)$ and mass loss. Mass loss studies were performed with 6 repetitions per time point, while rheology was performed twice per time point. The mass of the dry discs before degradation was determined $\left(m_{0}\right)$. Afterwards, the samples were incubated in $15 \mathrm{~mL}$ PBS buffer at $37^{\circ} \mathrm{C}$ in a shaker, and samples were removed and analyzed at the predetermined time points (typically every $12 \mathrm{~h}$ up to a maximum time of seven days). Subsequently, the samples were washed with $50 \mathrm{~mL}$ water for $8 \mathrm{~h}$, changing the water each hour to remove the salts of the buffer solution and the weight of the swollen degraded sample was determined $\left(m_{\mathrm{sw}-\mathrm{deg}}\right)$. The partially degraded samples were dried until constant weight was achieved and the dry weight after degradation was determined $\left(m_{\mathrm{deg}}\right) . H$ was calculated in accordance with Equation (10), and the remaining mass $\left(\mu_{\mathrm{rel}}\right)$ according to Equation (11), and the change in thermomechanical properties was evaluated as a function of degradation time.

$$
\begin{gathered}
H=\frac{m_{s w-d e g}-m_{d e g}}{m_{d e g}} \cdot 100 \% \\
\mu_{r e l}=100-\frac{m_{0}-m_{d e g}}{m_{0}} \cdot 100 \%
\end{gathered}
$$

\section{Conclusions}

In networks based on the reaction of GMA-gelatin with OEG $\alpha, \omega$-dithiols, the conformational freedom of gelatin chains is large enough so that triple helices are formed 
below the system-specific transition temperature $T_{\text {trans }}=25 \pm 3{ }^{\circ} \mathrm{C}$. The ability to form such triple helical regions increases notably with the $M_{\mathrm{n}}$ of the crosslinker, and there was also a tendency for higher triple helicalization with increasing dissimilarity between the amount of thiol and methacrylate groups. Triple helicity could be shown directly by WAXS as well as indirectly in temperature-dependent mechanical tests below and above $T_{\text {trans. }}$. The storage moduli of the studied hydrogels could be varied by $1-2$ orders of magnitude according to the composition, while Young's moduli and elongation at break varied by up to $50 \%$ between different compositions. The hydrogels were hydrolytically degradable, and mass loss as well as change of water uptake as well as rheological behavior was notable within a few days, which is remarkably faster compared to other gelatin-based hydrogels. This can be rationalized by the fact that the here investigated systems were only loosely crosslinked, and that bond cleavages took place primarily in the crosslinker rather than in the gelatin main chains. The ability of the systems to form triple helices could be used to enable a thermally-induced shape-memory effect compatible with physiological temperatures, which was shown in bending as well as in compression tests. Fixation of the temporary shape was based on the formation of triple helices as temporary physical net points. After disaggregation of the triple helices upon heating, entropy-elastic recoiling and shape recovery with excellent shape recovery rates $R_{\mathrm{r}}$ was observed. Additionally, the shape of the sample affected the ability for form fixation, with compressed samples having much higher $R_{\mathrm{f}}$ values than the bended samples. In the future, the here discussed shape-memory hydrogels may be of interest as multifunctional, actively-moving polymers that could be used in biomedicine, e.g., for self-anchoring devices.

Supplementary Materials: The following are available online at https:/ / www.mdpi.com/article/10 .3390 /ijms22115892/s1, Figure S1: Thioester formation by reaction of a thiol with a glycidylmethacrylate group on GMA-gelatin as side reaction increasing in importance with increasing amount of thiol, Figure S2: WAXS spectra of (A) G20_OEG1000(z), (B) G20_OEG1500(z), and (C) G20_OEG3400(z)

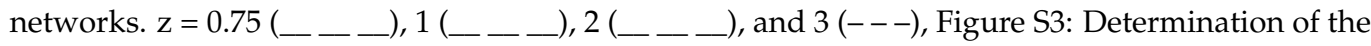
transition temperature by rheological compression tests. A) G20_OEG1000(1), B) G20_OEG1000(2), C) G20_OEG3400(1), D) G20_OEG3400(2), Figure S4: Tensile tests of G20_OEG1000(1) samples at $4{ }^{\circ} \mathrm{C}(\mathrm{A})$ and $55{ }^{\circ} \mathrm{C}(\mathrm{B}) . \sigma=$ stress, $\varepsilon=$ strain, Figure S5: Rheological behavior of G20_OEG1500(1) hydrogels after $1(-\lambda-), 1.5(-\mu-), 2(-\lambda-), 2.5(-\mu-), 3.5(-\mu-), 4(-\lambda-), 4.5(-\mu-), 5(-\lambda-), 5.5(-\mu-), 6.5(-\lambda-)$, and $6.5(-\mu-)$ days of hydrolytic degradation at $37^{\circ} \mathrm{C}$ at $\mathrm{pH}=7.4$, Figure S6: SDS-PAGE of the molar masses of the degradation products at $t=8 \mathrm{~d}$ : (1) standard, (2) G20_OEG1000(1), (3) G20_OEG1500(1), (4) G20_OEG3400(1). No larger gelatin fragments are observed, which suggests that hydrolysis primarily starts at the attached ester groups, Figure S7: Programming results in a helix as temporary shape; the original shape was recovered at $55^{\circ} \mathrm{C}$. For better visualization of the effect, the hydrogel stripes were stained with Coomassi blue, as original hydrogel appear to be transparent, Table S1: Gel content $(\mathrm{G})$ and volumetric degree of swelling $(\mathrm{Q})$ at defined temperatures for different hydrogel compositions, Table S2: Calculated values for relative triple helix content $\left(\mathrm{X}_{\mathrm{TH}}\right)$ and relative single helix content $\left(\mathrm{X}_{\mathrm{SH}}\right)$, as determined by means of WAXS measurements, Video S1: Shape recovery of a sample at $55^{\circ} \mathrm{C}$ programmed as helix (compare Figure S5).

Author Contributions: Conceptualization, A.T.N., M.B., A.L.; methodology: A.T.N., C.L., A.L.; formal analysis, A.T.N., C.L., K.K.J.-G.; supervision, A.T.N., M.B., A.L.; investigation, C.L., K.K.J.-G.; writing—original draft preparation, A.T.N., C.L.; writing—review and editing, K.K.J.-G., M.B., A.L.; project administration, A.L., funding acquisition, A.L. All authors have read and agreed to the published version of the manuscript.

Funding: This work was financially supported by the Helmholtz Association through programoriented funding and by the German Federal Ministry of Education and Research (BMBF) through project number 0315696A "Poly4-BioBB".

Institutional Review Board Statement: Not applicable.

Informed Consent Statement: Not applicable.

Data Availability Statement: The data that support the findings of this study are available from the corresponding author upon reasonable request. 
Conflicts of Interest: The authors declare no conflict of interest. M.B. and A.L. are inventors with patents in the field of shape-memory polymers. The funders had no role in the design of the study; in the collection, analyses, or interpretation of data; in the writing of the manuscript, or in the decision to publish the results.

$\begin{array}{ll}\text { Abbreviations } \\ \text { DMSO } & \text { dimethyl sulfoxide } \\ \text { DMTA } & \text { dynamic mechanical thermal analysis } \\ \varepsilon & \text { strain } \\ E & \text { Young's modulus } \\ E^{\prime} & \text { storage modulus (determined by DMTA) } \\ E^{\prime \prime} & \text { loss modulus (determined by DMTA) } \\ \varepsilon_{\mathrm{b}} & \text { elongation at break } \\ G & \text { gel content } \\ G^{\prime} & \text { storage modulus (determined by rheology) } \\ \text { GMA } & \text { glycidyl methacrylate } \\ H & \text { water uptake } \\ \text { OEG } & \text { oligo(ethylene glycol) } \\ Q & \text { volumetric swelling } \\ R_{\mathrm{f}} & \text { shape-fixity ratio } \\ R_{\mathrm{r}} & \text { shape-recovery ratio } \\ \text { SDS-PAGE } & \text { sodium dodecyl sulfate polyacrylamide gel electrophoresis } \\ \sigma_{\mathrm{max}} & \text { tensile strength } \\ \text { SMH } & \text { shape-memory hydrogel } \\ \text { SMP } & \text { shape-memory polymer } \\ T & \text { temperature } \\ \text { THF } & \text { tetrahydrofuran } \\ V & \text { volume } \\ \text { WAXS } & \text { wide-angle X-ray scattering } \\ X_{\mathrm{SH}} & \text { index of single helicity } \\ X_{\mathrm{TH}} & \text { index of triple helicity } \\ z & \text { thiol:methacrylate molar ratio } \\ & \end{array}$

\section{References}

1. Berg, J.M.; Tymoczko, J.L.; Stryer, L. Biochemistry. W.H. Freeman: Basingstoke, DE, USA, 2012.

2. Munoz, V.; Cerminara, M. When fast is better: Protein folding fundamentals and mechanisms from ultrafast approaches. Biochem. J. 2016, 473, 2545-2559. [CrossRef]

3. Hiramatsu, N.; Chiang, W.-C.; Kurt, T.D.; Sigurdson, C.J.; Lin, J.H. Multiple mechanisms of unfolded protein response-induced cell death. Am. J. Pathol. 2015, 185, 1800-1808. [CrossRef]

4. Lozano, P.; De Diego, T.; Iborra, J.L. Dynamic structure/function relationships in the $\alpha$-chymotrypsin deactivation process by heat and pH. Eur. J. Biochem. 1997, 248, 80-85. [CrossRef] [PubMed]

5. Lv, S.; Dudek, D.M.; Cao, Y.; Balamurali, M.; Gosline, J.; Li, H. Designed biomaterials to mimic the mechanical properties of muscles. Nature 2010, 465, 69-73. [CrossRef]

6. Bigi, A.; Panzavolta, S.; Rubini, K. Relationship between triple-helix content and mechanical properties of gelatin films. Biomaterials 2004, 25, 5675-5680. [CrossRef] [PubMed]

7. Lendlein, A.; Gould, O.E. Reprogrammable recovery and actuation behaviour of shape-memory polymers. Nat. Rev. Mater. 2019, 4, 116-133. [CrossRef]

8. Ruiz-Rubio, L.; Pérez-Álvarez, L.; Vilas-Vilela, J.L. Biodegradable shape-memory polymers. In Shape Memory Polymers, Blends and Composites; Parameswaranpillai, J., Siengchin, S., George, J.J., Jose, S., Eds.; Springer: Singapore, 2020; pp. $219-236$.

9. Lendlein, A.; Balk, M.; Tarazona, N.A.; Gould, O.E. Bioperspectives for shape-memory polymers as shape programmable, active materials. Biomacromolecules 2019, 20, 3627-3640. [CrossRef]

10. Shang, J.; Le, X.; Zhang, J.; Chen, T.; Theato, P. Trends in polymeric shape memory hydrogels and hydrogel actuators. Polym. Chem. 2019, 10, 1036-1055. [CrossRef]

11. Löwenberg, C.; Balk, M.; Wischke, C.; Behl, M.; Lendlein, A. Shape-memory hydrogels: Evolution of structural principles to enable shape switching of hydrophilic polymer networks. Acc. Chem. Res. 2017, 50, 723-732. [CrossRef] [PubMed] 
12. Yan, K.; Xu, F.; Wang, C.; Li, Y.; Chen, Y.; Li, X.; Lu, Z.; Wang, D. A multifunctional metal-biopolymer coordinated double network hydrogel combined with multi-stimulus responsiveness, self-healing, shape memory and antibacterial properties. Bio-mater. Sci. 2020, 8, 3193-3201. [CrossRef] [PubMed]

13. Li, N.; Chen, G.; Chen, W.; Huang, J.; Tian, J.; Wan, X.; He, M.; Zhang, H. Multivalent cations-triggered rapid shape memory sodium carboxymethyl cellulose/polyacrylamide hydrogels with tunable mechanical strength. Carbohydr. Polym. 2017, 178, 159-165. [CrossRef]

14. Cera, L.; Gonzalez, G.M.; Liu, Q.; Choi, S.; Chantre, C.O.; Lee, J.; Gabardi, R.; Choi, M.C.; Shin, K.; Parker, K.K. A bioinspired and hierarchically structured shape-memory material. Nat. Mater. 2021, 20, 242-249. [CrossRef] [PubMed]

15. You, Z.; Behl, M.; Grage, S.L.; Bürck, J.; Zhao, Q.; Ulrich, A.S.; Lendlein, A. Shape-Memory Effect by Sequential Coupling of Functions over Different Length Scales in an Architectured Hydrogel. Biomacromolecules 2020, 21, 680-687. [CrossRef]

16. Gu, L.; Jiang, Y.; Hu, J. Synthesis and Properties of Shape Memory Poly( $\gamma$-Benzyl-l-Glutamate)-b-Poly(Propylene Glycol)-bPoly( $\gamma$-Benzyl-1-Glutamate). Appl. Sci. 2017, 7, 1258. [CrossRef]

17. Bella, J. Collagen structure: New tricks from a very old dog. Biochem. J. 2016, 473, 1001-1025. [CrossRef]

18. Skrzeszewska, P.J.; Jong, L.N.; de Wolf, F.A.; Cohen Stuart, M.A.; van der Gucht, J. Shape-memory effects in biopolymer networks with collagen-like transient nodes. Biomacromolecules 2011, 12, 2285-2292. [CrossRef] [PubMed]

19. Chen, F.; Yang, K.; Zhao, D.; Yang, H. Thermal-and salt-activated shape memory hydrogels based on a gelatin/polyacrylamide double network. RSC Adv. 2019, 9, 18619-18626. [CrossRef]

20. Huang, J.; Zhao, L.; Wang, T.; Sun, W.; Tong, Z. NIR-Triggered Rapid shape memory PAM-GO-gelatin hydrogels with high mechanical strength. ACS Appl. Mater. Interfaces 2016, 8, 12384-12392. [CrossRef]

21. Zhang, Y.; Desai, M.S.; Wang, T.; Lee, S.-W. Elastin-Based Thermoresponsive Shape-Memory Hydrogels. Biomacromolecules 2020, 21, 1149-1156. [CrossRef]

22. Löwenberg, C.; Julich-Gruner, K.K.; Neffe, A.T.; Behl, M.; Lendlein, A. Salt-Induced Shape-Memory Effect in Gelatin-Based Hydrogels. Biomacromolecules 2020, 21, 2024-2031. [CrossRef]

23. Piluso, S.; Vukićević, R.; Nöchel, U.; Braune, S.; Lendlein, A.; Neffe, A.T. Sequential alkyne-azide cycloadditions for functionalized gelatin hydrogel formation. Eur. Polym. J. 2018, 100, 77-85. [CrossRef]

24. Maxwell, C.A.; Wess, T.J.; Kennedy, C.J. X-ray diffraction study into the effects of liming on the structure of collagen. Biomacromolecules 2006, 7, 2321-2326. [CrossRef]

25. Neffe, A.T.; Pierce, B.F.; Tronci, G.; Ma, N.; Pittermann, E.; Gebauer, T.; Frank, O.; Schossig, M.; Xu, X.; Willie, B.M.; et al. One step creation of multifunctional 3D architectured hydrogels inducing bone regeneration. Adv. Mater. 2015, 27, 1738-1744. [CrossRef] [PubMed]

26. Zaupa, A.; Neffe, A.T.; Pierce, B.F.; Nochel, U.; Lendlein, A. Influence of Tyrosine-Derived Moieties and Drying Conditions on the Formation of Helices in Gelatin. Biomacromolecules 2011, 12, 75-81. [CrossRef] [PubMed]

27. Elharfaoui, N.; Djabourov, M.; Babel, W. Molecular weight influence on gelatin gels: Structure, enthalpy and rheology. Macromol. Symp. 2007, 256, 149-157. [CrossRef]

28. Pierce, B.F.; Pittermann, E.; Ma, N.; Gebauer, T.P.; Neffe, A.T.; Hölscher, M.; Jung, F.; Lendlein, A. Viability of Human Mesenchymal Stem Cells Seeded on Crosslinked Entropy-Elastic Gelatin-Based Hydrogels. Macromol. Biosci. 2012, 12, 312-321. [CrossRef] [PubMed]

29. Piluso, S.; Lendlein, A.; Neffe, A.T. Enzymatic action as switch of bulk to surface degradation of clicked gelatin-based networks. Polym. Adv. Tech. 2017, 28, 1318-1324. [CrossRef] 